\title{
ASSESSMENT OF SLOPE STABILITY USING PS-INSAR TECHNIQUE
}

\author{
Ramji Dwivedi ${ }^{\mathrm{a}, *}$, Prabal Varshney ${ }^{\mathrm{a}}$, Ashutosh. Tiwari ${ }^{\mathrm{b}}$, Ajai Kumar Singh $^{\mathrm{b}}$, Onkar Dikshit $^{\mathrm{a}}$ \\ ${ }^{a}$ Geographic Information System (GIS) Cell, MNNIT Allahabad, Allahabad-211004, UP (ramiitk07@gmail.com, \\ prabal09102199ece@gmail.com, aksingh@mnnit.ac.in) \\ b Department of Civil Engineering, IIT Kanpur, Kanpur-208016, UP (ashutoshtiwari796@gmail.com, onkar@iitk.ac.in)
}

\section{Commission VIII, WG VIII/1}

KEY WORDS: PS-InSAR, Landslide, StaMPS, Deformation.

\begin{abstract}
:
In this research work, PS-InSAR approach is envisaged to monitor slope stability of landslides prone areas in Nainital and Tehri region of Uttarakhand, India. For the proposed work, Stanford Method for Persistent Scatterers (StaMPS) based PS-InSAR is used for processing ENVISAT ASAR C-Band data stacks of study area which resulted in a time series 1D-Line of Sight (LOS) map of surface displacement. StaMPS efficiently extracted the PS pixels on the unstable slopes in both areas and the time series 1D-LOS displacement map of PS pixels indicates that those areas in Nainital and Tehri region have measurement pixels with maximum displacement away from the satellite of the order of $22 \mathrm{~mm} /$ year and $17.6 \mathrm{~mm} /$ year respectively.
\end{abstract}

\section{INTRODUCTION}

Synthetic aperture radar (SAR) is an advanced technology of radar community. It is an active microwave remote sensing mechanism which is capable of monitoring geophysical parameters (e.g. displacement vector) of earth features. It provides data in various formats which can be easily absorbed by the researchers as well as by the industry. Interferometric SAR (InSAR) uses two or more SAR images at different acquisition time to generate interferograms and digital elevation model (DEM), and thereby determine the change in the position of resolution cells in the satellite line of sight (LOS). It is widely used for deformation monitoring purposes but severely affected from the errors such as temporal and spatial decorrelation.

In order to overcome the aforementioned limitations of InSAR, permanent scatterer InSAR (PS-InSAR) was abstracted and devolved by Ferretti et al. (2000). PS-InSAR identifies measurement pixels known as permanent scatterer (PS) with stable amplitude and phase history over a long interval of time. Examples of such PS candidates are manmade objects such as buildings, roofs etc. Although PS-InSAR is more accurate and consistent it too suffers from some limitations i.e. less PS density in non-urban areas, one dimensional representation of 1D-LOS (Greif and Vlcko, 2013).

In order to remove the aforesaid limitations, Stanford Method of Persistent Scatterer (StaMPS) approach is conceptualized and developed by Hooper et al. (2007). StaMPS based PS-InSAR method uses spatial correlation of interferogram phase to identify phase stable pixels even with low amplitude stability which makes the approach capable of detecting PS pixels in non-urban areas.

In this research work, we have applied StaMPS based PSInSAR processing for assessing the slope stability in Nainital and Tehri regions of Uttarakhand, India.

\section{STUDY AREA AND SATELLITE DATASET}

Landslide is the one of the most threatening geo-hazards of the Himalaya causing colossal damages to the infrastructure and livelihood of common people. Therefore, two Himalyan town of Uttarakhand, India-Nainital and Tehri are under our scanner in this research work.

\subsection{Geological settings of study areas}

Nainital, is a popular hill station in the state of Uttarakhand at the Kumaon foothills of the lesser Himalayas. Nainital township is situated in a valley containing a kidney-shaped lake at an altitude of 2,084 metres above sea level and surrounded by mountains. The town has experienced disastrous landslide events in 1867, 1880, 1893, 1898, 1924 and 1998 according to (Sharma, 2006).

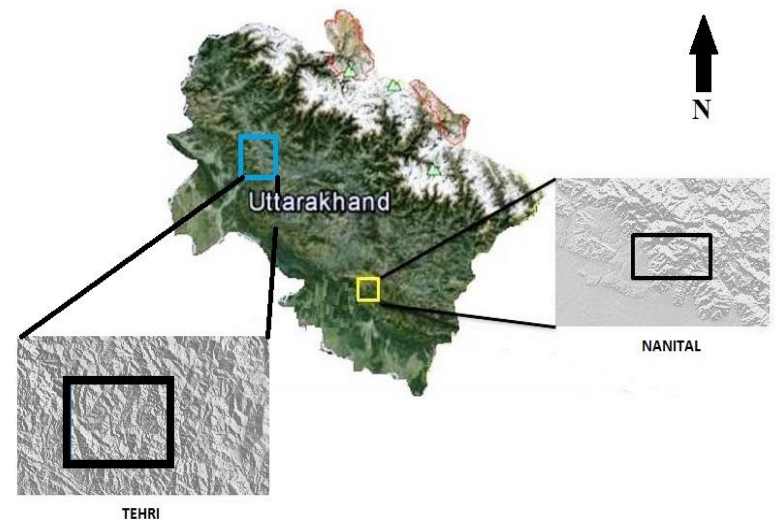

Figure 1. Study area location

Tehri town is inhabited near Tehri reservoir at the union of Bhagirathi and Bhilangana rivers at an altitude of $1,750 \mathrm{~m}$ $(5,740 \mathrm{ft})$. In the past, much causality has been reported because

\footnotetext{
* Corresponding author (ramiitk07@gmail.com)
} 
of the multi events of landslide induced by Tehri reservior. Also in December 2010, debris from the landslip has blocked a division tunnel forcing a stop to generation of electricity. This has caused a loss of more than Rs 100 crore. Due to aforesaid facts, it has become an area of interest for this slope stability study.

\subsection{Satellite Dataset of Nainital and Tehri}

In order to monitor the critical slopes around Nainital lake, we have processed 13 descending ENVISAT C-Band ASAR images of track 248 (frame: 3015) acquired between October 2008 to August 2010.. Similarly, to monitor critical slopes around Tehri reservoir, 16 Envisat ASAR C-Band SLC images of track 291 (frame: 83) acquired between January 2009 to July 2010 are used. ASAR image of $25^{\text {th }}$ December 2009 and $9^{\text {th }}$ October 2009 is chosen as the master image for Nainital and Tehri region respectively based on minimizing the temporal, Doppler and perpendicular baseline $(\mathrm{B} \perp)($ Hooper et al., 2007)

The aforementioned dataset is presented in Table 1 and 2 along with the critical perpendicular baseline length with respect to master image, acquisition date, orbit number and Doppler centroid frequency. Apart from the SLC images, a $90 \mathrm{~m}$ resolution SRTM Digital Elevation Model (DEM) (Figure 1) is used to remove the topographic phase from the differentially corrected interferogram. The orbital corrections are done with the help of precise orbits obtained from ESA. The DORIS precise orbits for the year 2008, 2009 and 2010 are used to remove orbital bias.

\begin{tabular}{|c|c|c|c|c|}
\hline $\begin{array}{c}\text { S. } \\
\text { No. }\end{array}$ & $\begin{array}{c}\text { Acquisition } \\
\text { date }\end{array}$ & $\begin{array}{c}\text { Orbit } \\
\text { No. }\end{array}$ & $\begin{array}{l}\mathrm{B}_{\perp} \\
(\mathrm{m})\end{array}$ & $\begin{array}{c}\text { Doppler } \\
\text { Centroid(Hz) }\end{array}$ \\
\hline 1. & 31Oct2008 & 34871 & 155.6 & 166.231 \\
\hline 2. & 05Dec2008 & 35372 & 43.7 & 168.060 \\
\hline 3. & 07Aug2009 & 38879 & 44.9 & 170.098 \\
\hline 4. & 11Sep2009 & 39380 & 476.3 & 165.710 \\
\hline 5. & 16Oct2009 & 39881 & -161.1 & 163.154 \\
\hline 6. & 20Nov2009 & 40382 & 377.8 & 171.735 \\
\hline 7. & 25Dec2009 & $\mathbf{4 0 8 8 3}$ & $\mathbf{0}$ & $\mathbf{1 6 2 . 4 3 7}$ \\
\hline 8. & 29Jan2010 & 41384 & 339.2 & 171.353 \\
\hline 9. & 05Mar2010 & 41885 & 28.0 & 168.613 \\
\hline 10. & 09Apr2010 & 42386 & 324.5 & 172.944 \\
\hline 11. & 18Jun2010 & 43388 & 252.8 & 182.534 \\
\hline 12. & 23Ju12010 & 43889 & -65.2 & 177.749 \\
\hline 13. & 27Aug2010 & 44390 & -37.9 & 177.370 \\
\hline
\end{tabular}

Table 1. Satellite data stacks for Nainital Area

\begin{tabular}{|l|l|l|l|c|}
\hline $\begin{array}{l}\text { S. } \\
\text { No }\end{array}$ & $\begin{array}{l}\text { Acquisition } \\
\text { date }\end{array}$ & $\begin{array}{l}\text { Orbit } \\
\text { No. }\end{array}$ & $\mathrm{B}_{\perp}(\mathrm{m})$ & $\begin{array}{l}\text { Doppler } \\
\text { Centroid(Hz) }\end{array}$ \\
\hline 1. & 12Jan 2009 & 36417 & 301.6 & 172.014 \\
\hline 2. & 16Feb 2009 & 36417 & 305.1 & 348.914 \\
\hline 3. & 23Mar2009 & 36918 & 651.1 & 169.777 \\
\hline 4. & 27Apr 2009 & 37419 & 251.1 & 165.833 \\
\hline 5. & 01Jun 2009 & 37920 & 390.4 & 171.174 \\
\hline 6. & 06Jul 2009 & 38421 & 207.8 & 173.297 \\
\hline 7. & 10Aug2009 & 38922 & 173.2 & 173.608 \\
\hline 8. & 14Sep2009 & 39423 & 598.7 & 176.089 \\
\hline 9. & 19Oct2009 & $\mathbf{3 9 9 2 4}$ & $\mathbf{0}$ & 169.287 \\
\hline 10 & 23Nov2009 & 40924 & 50.33 & 172.812 \\
\hline 11 & 01Feb2010 & 41425 & 567.8 & 174.730 \\
\hline
\end{tabular}




$$
D_{A}=\frac{\sigma_{A}}{\mu_{A}}
$$

The candidates are tested for phase stability using a measure $\gamma_{X}$ stated in the following equation Hooper et al. (2007):

$$
\gamma_{x}=\frac{1}{N}\left|\sum_{i=1}^{N} \exp \left\{\sqrt{-1\left(\varphi_{x, i}-\tilde{\varphi}_{x, i}-\Delta \hat{\phi}_{\theta_{\theta, x, i}}^{u}\right)}\right\}\right|
$$

$\mathrm{N}$ represents the number of interferograms, $\varphi_{x, i}$ represents the wrapped phase value of the $x^{\text {th }}$ pixel in the $i^{\text {th }}$ interferogram, $\tilde{\varphi}_{x, i}$ is the mean value of $\varphi_{x, i}$ and $\Delta \hat{\phi}_{\theta_{\theta, x}}^{u}$ represents the change in the spatially uncorrelated part of the look angle error for the $x^{\text {th }}$ pixel in the $i^{\text {th }}$ interferogram.

\subsection{PS Detection}

The pixels which satisfy the convergence of $\gamma_{X}$ to the threshold value are picked as PS pixels. The selected PS pixels contain a wrapped phase value, which is to be unwrapped, i.e. they must be added by an estimated number of phase cycles of $2 \pi$ to retrieve the original phase value, a process known as phase unwrapping. Other nuisance terms, such as the master and atmospheric error terms, spatially uncorrelated look angle error, satellite orbit errors are also estimated and removed from the unwrapped phase $\phi_{x, i}$ of the detected PS pixels.

\subsection{Displacement Estimation}

The displacement can then be estimated using the phase values of the individual PS pixels. A 1D Line of Sight (LOS) displacement map is generated as an output of the StaMPS method.

\section{RESULTS AND DISCUSSION}

\subsection{Time series displacement analysis of Nainital}

In this section, results of StaMPS based PS-InSAR processing of the 13 Envisat ASAR SLC images of Nainital and its surrounding area is presented. With 13 SLC images, 12 geocoded interferograms are generated as shown in Figure 2.

The parameters used for StaMPS based PS-InSAR processing are shown in Table 3. Initially, more than 100000 PS candidates were selected using a $D_{A}$ value of 0.35 with the area being divided into 6 patches and finally 5606 pixels were detected as PS pixels. The processing resulted in generation of time series displacement of PS pixels in satellite LOS as shown in Figure 3 ( $\mathrm{X}$ and $\mathrm{Y}$ axis represent longitude and latitude respectively) with cold and warm colours representing movements towards and away from the satellite respectively.
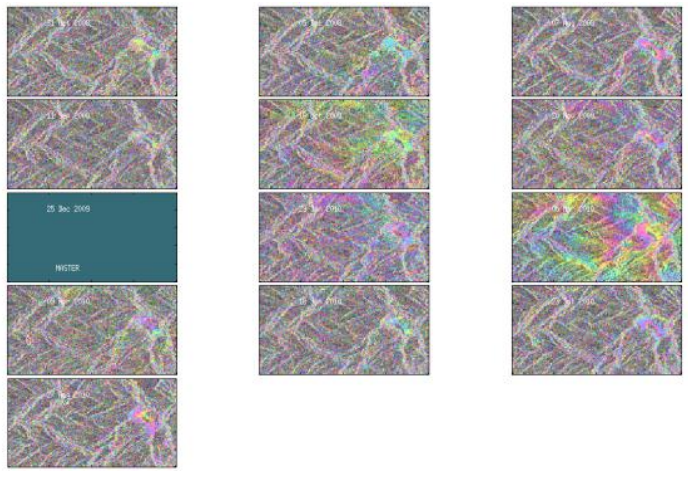

Figure 2. Interferograms for the Nainital region. The image acquired on 25th December 2009 is chosen as the master image.

\begin{tabular}{|l|c|}
\hline \multicolumn{1}{|c|}{ Parameters } & $\begin{array}{c}\text { Value of } \\
\text { parameter }\end{array}$ \\
\hline Number of SLC images $(\mathrm{N})$ & 13 \\
\hline Pixel grid size & 50 \\
\hline Amplitude dispersion threshold $\left(D_{A}\right)$ & 0.35 \\
\hline Rate of convergence $\left(\gamma_{X}\right)$ & 0.005 \\
\hline Number of patches in azimuth & 3 \\
\hline Number of patches in range & 2 \\
\hline $\begin{array}{l}\text { Overlapping pixel between patches in } \\
\text { azimuth }\end{array}$ & 200 \\
\hline
\end{tabular}

Table 3. Parameters for StaMPS processing of Nainital region

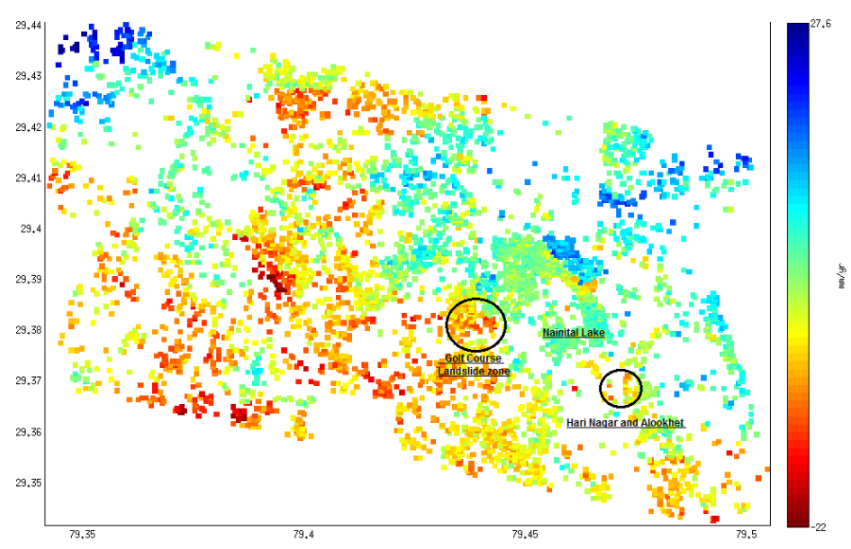

Figure 3. 1D-LOS displacement plot of Nainital region

Although in recent times no major landslip activity has been reported but there are a few number of unstable slope zones (Golf course landslide, Hari nagar-Aloo Khet) identified after PS-InSAR processing as circled in Figure 3.

\subsection{Time series displacement analysis of Tehri}

In this section, results of StaMPS based PS-InSAR processing of the 16 Envisat ASAR SLC images of Tehri region are presented. With 16 SLC images, 15 geocoded interferograms are generated as shown in Figure 4. The parameters used for StaMPS based PS-InSAR processing are shown in Table 4. Initially, more than $12,50,000$ PS candidates were selected based on the $D_{A}$ value of 0.45 and 19,549 PS pixels were detected. The processing resulted in generation of time series displacement plot as shown in Figure 5. 


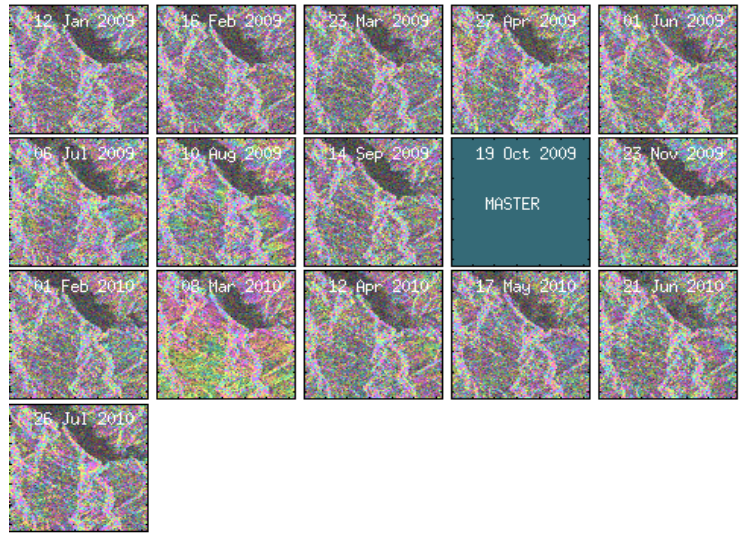

Figure 4. Interferograms for the Tehri region. The image acquired on 19th October 2009 is chosen as the master image.

\begin{tabular}{|l|c|}
\hline \multicolumn{1}{|c|}{ Parameters } & $\begin{array}{c}\text { Value of } \\
\text { parameter }\end{array}$ \\
\hline Number of SLC images $(\mathrm{N})$ & 16 \\
\hline Pixel grid size & 50 \\
\hline Amplitude dispersion threshold $\left(D_{A}\right)$ & 0.45 \\
\hline Rate of convergence $\left(\gamma_{X}\right)$ & 0.005 \\
\hline Number of patches in azimuth & 3 \\
\hline Number of patches in range & 2 \\
\hline $\begin{array}{l}\text { Overlapping pixel between patches in } \\
\text { azimuth }\end{array}$ & 200 \\
\hline
\end{tabular}

Table 4. Parameters for StaMPS processing of Tehri region

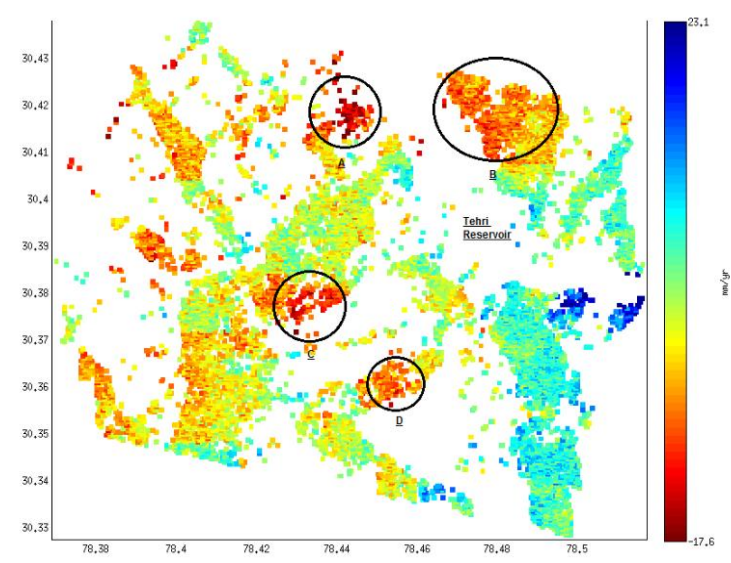

Figure 5. 1D-LOS displacement plot of Tehri region

In the time series displacement plot (Figure 5), few unstable slope zones with warm colours are marked as A, B, C and D. A and $\mathrm{B}$ regions are near to Tehri reservoir and have PS pixel with maximum displacement of $17.6 \mathrm{~mm} /$ year. Another unstable slope zone $(\mathrm{C}, \mathrm{D})$ near to New Tehri township is identified with warm colours.

\section{CONCLUSION}

We have successfully applied StaMPS based PS-InSAR processing in Nainital and Tehri regions of Uttarakhand, India. Time series displacement plots clearly show that there are various patches of area having significant displacement away from the satellite LOS and are probable unstable zones. We also draw conclusion that the results achieved after PS-InSAR approach can be a valuable input in comprehensive assessment the slope stability, if supplemented with other sub-surface investigation. In future, a thorough field survey is essentially required to comment on the present status of these unstable zones. Further, if the ASAR images in satellite data stacks are increased, a more precise estimation of the deformation pattern can be observed. StaMPS based Small Baseline Subset (SBAS) can also be investigated for this study.

\section{REFERENCES}

Crosetto, M., Crippa, B., and Biescas, E., 2005. Early detection and in-depth analysis of deformation phenomena by radar interferometry. Engineering Geology 79(1-2), 81-91.

Ferretti, A., Prati, C., and Rocca F., 2000. Nonlinear subsidence rate estimation using Permanent Scatterers in differential SAR, IEEE Trans. GARS Vol. 38, pp. 2202 - 2212, September 2000.

Hanssen, R.F., 2003.Subsidence monitoring using contiguous and PS-InSAR: Quality assessment based on precision and reliability, Proceedings, 11th FIG Symposium on Deformation Measurements, Santorini, Greece.

Hooper, A., Zebker, H., Segall, P., and Kampes., B.,2004. A new method for measuring deformation on volcanoes and other natural terrains using InSAR persistent Scatterers, Geophysical Research Letters, Vol. 31.

Hooper, A., Segall, P., and Zebker, H., 2007. Persistent Scatterer InSAR for Crustal Deformation Analysis, with Application to Volcan Alcedo, Galapagos, Journal of Geophysical Research, Vol. xxx, xxxx,

Lyons, S., and Sandwell, D., 2003. Fault creep along the southern San Andreas from interferometric synthetic aperture radar, permanent scatterers, and stacking, Journal of Geophysical Research, 108(B1), 2047-2070.

Sharma, V. K. 2006. Zonation of landslide hazard for urban planningcase study of Nainital town, Kumaon Himalaya, India, IAEG paper number 191.

Greif, V., and Vlcko, J., 2013. Application of the PS-InSAR Technique for the Post-Failure Landslide Deformation Monitoring at Lubietova Site in Central Slovakia, Landslide Science and Practice, Vol. 2, DOI 10.1007/978-3-642-314452_2, Springer-Verlag Berlin Heidelberg. 